\title{
Development of PC Worker's Management System in PC Training Room and Office by Using loT Technology
}

\author{
Keiichi Abe, Yuki Takabayashi and Masao Isshiki \\ Kanagawa Institute of Technology, Atsugi City, Kanagawa 243-0292, Japan
}

\begin{abstract}
At present time, there has been a demand for management systems that can survey and monitor a PC (personal computer) practice room, movement of people in an office, situation of utilization of facilities and so on in real time without causing psychological stress. For example, PC administrators in Japanese national educational institutions must report operation status of PC practice rooms once a year. But, there is currently no system for automatically recording PC operating situations. Therefore, the burden on the PC administrators is big. In this study, we aimed at systems for accurately managing the sitting and work time without psychologically stressing PC users. This time, we propose uniform management systems of sitting and work time using smart tap node and mat sensor node by IoT (Internet of Things) technology. The smart tap was connected to PCs to acquire the operating status of the PCs. In parallel with this smart tap, the mat sensor was used to acquire human presence state. By calculating binary data representing the PC operating status and human presence state from the two sensing data (smart tap and mat sensor) by the proposed technique, we can exactly calculate wasteful power consumption etc. The use of IoT technology makes it unnecessary to use large installation services when introducing our system. Therefore, this our proposal system can be easily installed even by unskilled workers.
\end{abstract}

Key words: PC worker's management system, smart tap node, mat sensor node, IoT technology, sensor network.

\section{Introduction}

There is a demand for a system which can survey and monitor the use situation of facilities and movements of persons in a PC (personal computer) practice room or office in real time without psychologically stressing the users [1]. For example, an annual report of the operation situation (the number of users, use time) of PC practice rooms is required in some Japanese educational institutions. This is considerably burdensome for system managers because the tasks of recording, counting, and reporting the operation situation typically rely on manual work, with poor utilization of IT tools.

In recent years, universities and other educational institutions use PCs frequently regardless of the field. PCs have also been essential in businesses as well as in educational institutions. With the number of users

Corresponding author: Keiichi Abe, doctor of philosophy in informatics, research fields: embedded system, consumer system and sensor network. and devices increased to dozens, or even hundreds, the burden on managers has been rapidly increasing.

Therefore, in this study, we propose a management system for administration in a PC practice room or office and the PC operation situation. The system described in this paper utilizes IoT (Internet of Things) technology by wireless communication (Wi-Fi). This system requires no major construction and can be easily installed even by unskilled workers.

This paper is organized as follows. Chapter 2 describes related technologies. Chapter 3 gives an overview of the proposed system, and Chapter 4 details the prototype development. In Chapter 5, we will describe the evaluation results of the prototype. In Chapter 6 we will conclude this research as a summary.

\section{Related Works (or Study)}

There are systems [2-5] confirming entry and exit by an IC (integrated circuit) card as a PC user's 
presence confirmation technique in a conventional office and PC classroom.

Meanwhile, there are studies on automated systems that use iBeacon technology as a system that automates entry and exit time management within the office [6], a handsfree entrance and exit/presence management system [7], and a study of an attendance management system using a camera [8-10].

Those previous studies enable us to grasp the entering and leaving times of users, but there is the problem that we cannot exactly know their actual PC work time. So, we consider a system for exactly managing the attendance time of users and the PC work time. Using a camera would certainly enable an exact, real-time monitoring of the work time. However, constant monitoring by camera may make some users feel psychological stressed.

Therefore, in this study, we propose a system for real-time administration of the attendance time of users in a PC training room or office and the $\mathrm{PC}$ work time.

Unlike the conventional studies which require big installation work for system introduction, our system requires no such big work and can be installed even by unskilled workers.

\section{PC work Management System}

\subsection{System Concept}

\subsubsection{Installation Location}

The system is supposed to be installed in a computer room such as company office or educational institution.

\subsubsection{PC to be Monitored}

The use of desktop PCs is assumed. Mobile computers are excluded.

3.1.3 Person to be monitored

$\mathrm{PC}$ users in the office and PC training room.

\subsubsection{Scale of Data Management}

On the assumption that this system will be used in a PC practice room etc. in corporate offices and educational institutions, the system should manage the maximum number of about 100 people.

\subsubsection{Method of Data Collection}

In this system, sensor data are collected from various sensor nodes by wireless communication, such as Wi-Fi standards. One data collection PC (host computer) also uses the same wireless communication standard as the sensor node, and collects data from various sensor nodes with a dedicated application.

\subsubsection{Number of Sensor Nodes Installed}

The number of various sensor nodes may be about 2 nodes for each PC user.

\subsubsection{This System Installation Method}

This system uses a sensor node equipped with a wireless communication function (Wi-Fi, IEEE 802.15 .4 , etc.). This makes it possible to install the system with a free layout. This makes it easier for people who do not have technical skills to install it and, as a result, reduces the cost of introducing the system.

\subsubsection{Management Contents of PC Users}

Below are the management contents of PC users such as offices handled in this system.

(1) Grasp the number of PC users;

(2) Manage presence status of PC users;

(3) Distinguish between the PC work time and work time other than $\mathrm{PC}$ by the user, and find the actual use time of the $\mathrm{PC}$;

(4) Count and manage the time when the PC is running with no user present and wasting electricity.

\subsection{Summary of PC Work Management System}

Fig. 1 shows the outline of the proposed system for managing the PC work situation of PC users in offices and the like.

In this system, in order to monitor the operation status of each desktop PC installed in an office etc., the smart tap always measures the power of the desktop PC being used by the smart tap and sends the result to the host computer for data collection. Also, in each PC, a commercially available mat sensor detects the existence of the PC user, and the detection result is 


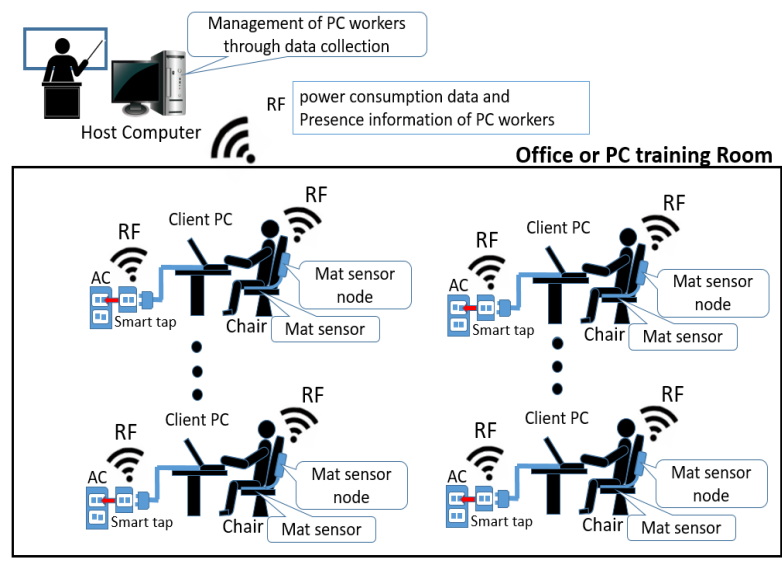

Fig. 1 Overview of PC work management system.

transmitted to the host computer by wireless communication such as Wi-Fi. A commercially available mat sensor equipped with a wireless communication function is referred to as a mat sensor node here. The smart tap and mat sensor node we developed was used this time.

In the proposed system, the number of PC users is calculated from presence/absence of presence of PC users from the mat sensor node. Also, based on the power consumption of the PC acquired from the smart tap and the presence or absence of the presence of the person by the mat sensor, the time when the PC user actually used the PC (hereinafter referred to as the PC working time) is accurately calculated. This calculation method will be described in detail in Section 3.3, but this algorithm was implemented in a dedicated application of the host computer.

\subsection{Proposal of Calculation Method of Sitting and Work Time}

Section 3.3 explains calculation method of sitting and work time. From the two kinds of sensor data acquired with the smart tap and mat sensor, we can estimate the activity of the user in four ways as shown in Table 1.

Firstly, we understand the ON/OFF state of the PC from the power consumption information of the smart tap. An output of " 1 " from the smart tap shows that the $\mathrm{PC}$ is $\mathrm{ON}$, and " 0 " shows that the PC is OFF. In the system, the power consumption threshold is $15 \mathrm{~W}$.
Therefore, if it exceeds $15 \mathrm{~W}$, the output is " 1 " when the power consumption exceeds $15 \mathrm{~W}$ and " 0 " when less than $15 \mathrm{~W}$. On the other hand, an output of "1" from the mat sensor indicates a state where someone is in the chair, and "0" indicates no one is in the chair. It is possible to manage one PC by the two pieces of sensor information.

When $\mathrm{A}=0$ and $\mathrm{B}=0$, the $\mathrm{PC}$ is in OFF state and no user is present, hence "Absence". $\mathrm{A}=0$ and $\mathrm{B}=1$ indicates that the PC is in the OFF state, but because someone is present, it indicates "Work time other than $\mathrm{PC}$ ". When $\mathrm{A}=1$ and $\mathrm{B}=0$, the $\mathrm{PC}$ is in the $\mathrm{ON}$ state, but because no one is present, it indicates "Wasted electric use time". When $\mathrm{A}=1$ and $\mathrm{B}=1$, since the user is present while the $\mathrm{PC}$ is $\mathrm{ON}$, this state is judged to be "PC work time" in this study.

When the output of the smart tap is A and the output of the mat sensor is B, the output $\mathrm{W}$ in the absence state, the output $\mathrm{X}$ in the working state other than the $\mathrm{PC}$, the output $\mathrm{Y}$ in the waste electric utilization state, the output $\mathrm{Z}$ in the $\mathrm{PC}$ working state, the following Eqs. (1)-(4) are derived from Table 1.

Our system defines the output $Z$ of Eq. (4) as PC

$$
\begin{aligned}
W & =\bar{A} \cdot \bar{B} \\
\mathrm{X} & =\bar{A} \cdot \bar{B} \\
\mathrm{Y} & =\mathrm{A} \cdot \bar{B} \\
\mathrm{Z} & =\mathrm{A} \cdot \mathrm{B}
\end{aligned}
$$

working, but a person sitting in the chair is not necessarily doing PC work but may actually be doing other work than PC. Therefore, in this research, in order to distinguish between PC work and non-PC work, the sleep function of the $\mathrm{PC}$ is utilized in addition

Table 1 Each sensor information and action estimate of the person.

\begin{tabular}{lll}
\hline $\begin{array}{l}\text { A } \\
\text { Smart tap } \\
\text { (PC-ON/OFF) }\end{array}$ & $\begin{array}{l}\text { B } \\
\text { Mat sensor } \\
\text { (Sitting/Not sitting) }\end{array}$ & $\begin{array}{l}\text { Action estimate of the } \\
\text { person }\end{array}$ \\
\hline 0 & 0 & $\begin{array}{l}\text { Absence } \\
\text { (PC-OFF/Not sitting) }\end{array}$ \\
0 & 1 & $\begin{array}{l}\text { Work time other than PC } \\
\text { (PC-OFF/Sitting) }\end{array}$ \\
1 & 0 & $\begin{array}{l}\text { Wasted electric use time } \\
\text { (PC-ON/Not sitting) } \\
\text { PC work time } \\
\text { (PC-ON/Sitting) }\end{array}$ \\
\hline
\end{tabular}


to the two kinds of sensor data acquired from the smart tap and mat sensor node. More specifically, while the $\mathrm{PC}$ is $\mathrm{ON}$, if the user sitting on the chair does not perform any $\mathrm{PC}$ operation for a certain time, the PC automatically goes to the sleep mode and its power is turned off. This indicates the beginning of the work other than PC.

\section{Prototype System Implementation}

Chapter 4 describes the prototype development of the system proposed by this paper. In the prototype developed this time, in order to monitor PC work situation of PC users, one smart tap and one mat sensor node were arranged for one PC user as shown in Fig. 2.

One host computer was installed to collect sensor information from each sensor node. Also, communication between each sensor node and the host computer was performed through Wi-Fi wireless communication via a $\mathrm{Wi}-\mathrm{Fi}$ wireless communication router. In Chapter 4, prototype development of each wireless sensor node, host computer, etc. will be described in detail.

\subsection{Wireless Smart Tap Node}

The smart tap node with wireless communication developed this time calculates the total value of current consumption in CT sensor (KM20-CTF-50A/OMRON). Power (apparent power) is simply calculated from the product of the voltage that is constant at $\mathrm{AC} 100 \mathrm{~V}$ and the measured current. Power consumption information is delivered to the host computer via Wi-Fi. Commercially available $\mathrm{MCU}+$ wireless module (ESP-WROOM-02/Espressif Systems) was used for Wi-Fi communication [11]. It has MCU (micro controller unit) built in and can be used like Arduino. The Wring language, which is a C-based language, was used for the software development this time.

\subsection{Wireless Mat Sensor Node}

In this system, the presence or absence of a user sitting in a chair was detected by using a mat sensor (M-A4/Takenaka Engineering). As for the Wi-Fi communication, a wireless module with built-in MCU(ESP-WROOM-02/Espressif Systems) was used like the smart tap node. Fig. 3 shows a photograph with mat sensor node mounted.

\subsection{Firmware of MCU with Wireless Node}

Fig. 4 shows flowchart of data transmission firmware for MCU (Type: ESP-WROOM-02) with wireless node.

The wireless module with built-in MCU operates to transmit the measurement result to the host computer by Wi-Fi communication.

To allow for data transmission from multiple nodes, the IP address and port number of the host computer are set in advance in the MCU so that the destination can be specified. In this study, UDP/IP communication

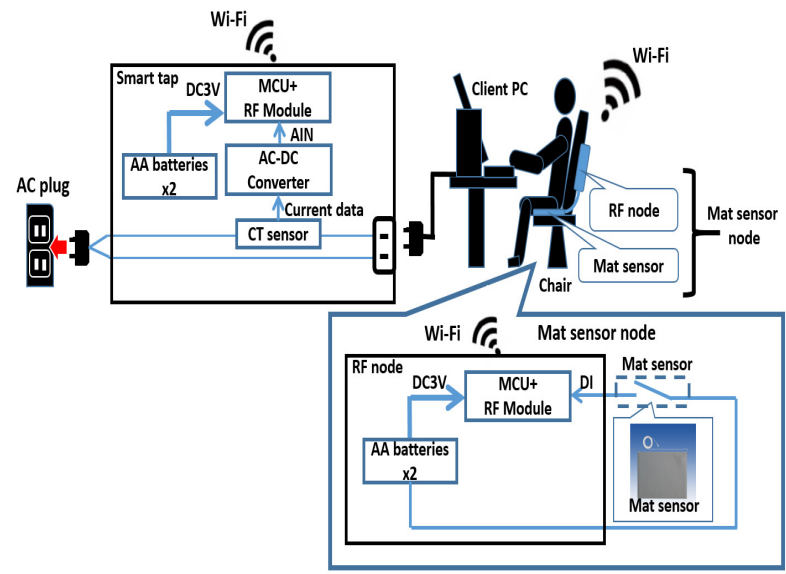

Fig. 2 Configuration of smart tap and mat sensor node installed per $\mathbf{P C}$.

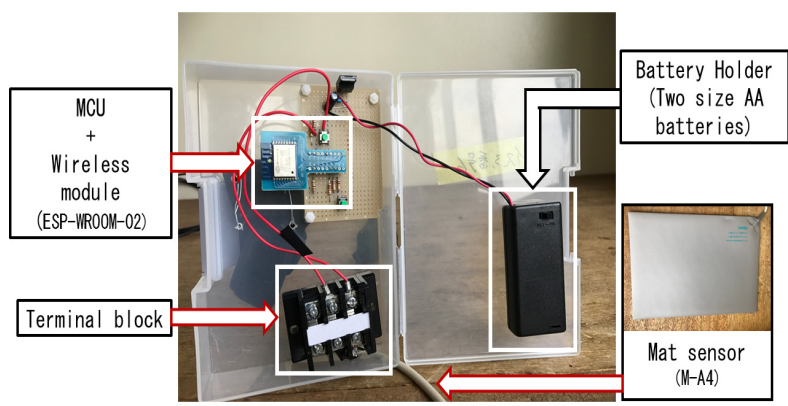

Fig. 3 Overview of mat sensor node. 


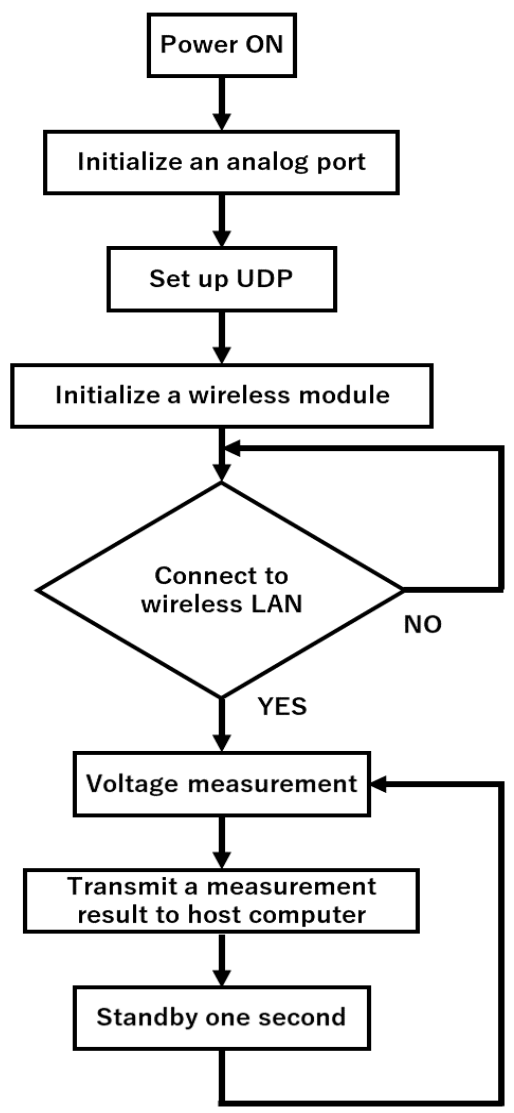

Fig. 4 Flowchart of data transmission firmware for MCU with wireless node.

was used as the communication method.

\subsection{Application Software of Host Computer}

On the host computer, we developed an application that can display and store the collected data in real time (Fig. 5).

This application calculates PC work time and wasted electric use time from the two pieces of information including the person's presence status and PC work situation, and displays them on the screen. Work time other than PC and absence time is also calculated and displayed on the PC screen.

This GUI (graphical user interface) application was developed in Visual Basic 2015 development environment.

\section{Evaluation of the System}

In this Chapter 5, the evaluation method and the evaluation result of the prototype system developed this time will be described.

\subsection{Experimental Environment}

Fig. 6 shows a layout of the smart tap node and mat sensor node by our system. The empirical evaluation of the prototype was carried out at the Kanagawa Institute of Technology $\mathrm{C} 2$ building 6th floor the Room No. E602 (ABE-Laboratory). The evaluation period is from May 8, 2017 to May 26, 2017. In this study, the PC operation status and PC work situation for two subjects were measured.

This time, one host computer was used for data management. Smart taps and mat sensors were installed on each of the two PCs. Fig. 7 shows actual experiment image. A real-time video was also simultaneously acquired and used as the "correct answer" data. For the real time display, we used the application created in Visual Basic 2015.

Actual work time etc. was obtained from the correct answer data and compared with aggregated data in prototype application for evaluation. As shown in Fig. 7,

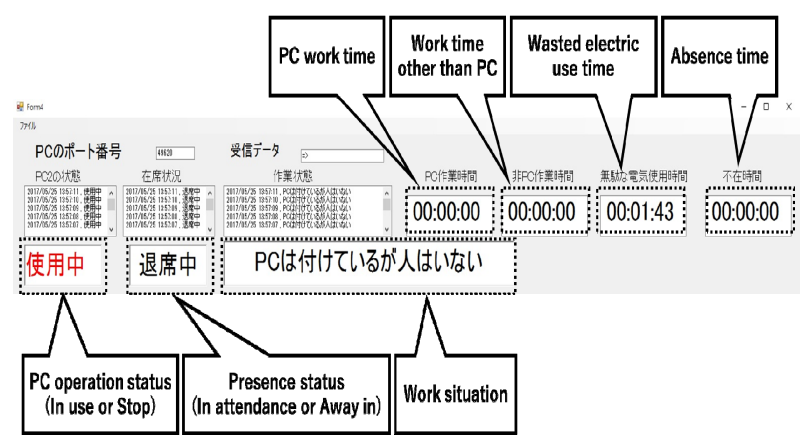

Fig. 5 GUI application on host computer.

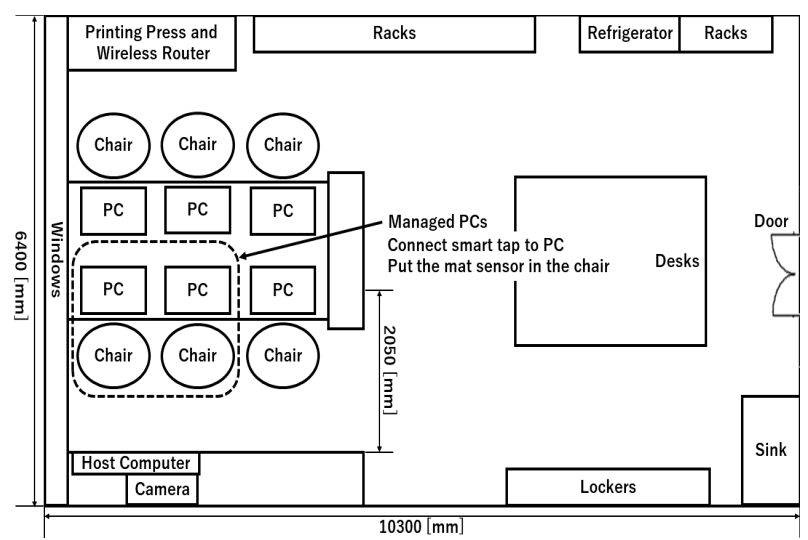

Fig. 6 Layout of smart tap node and mat sensor node by our system. 


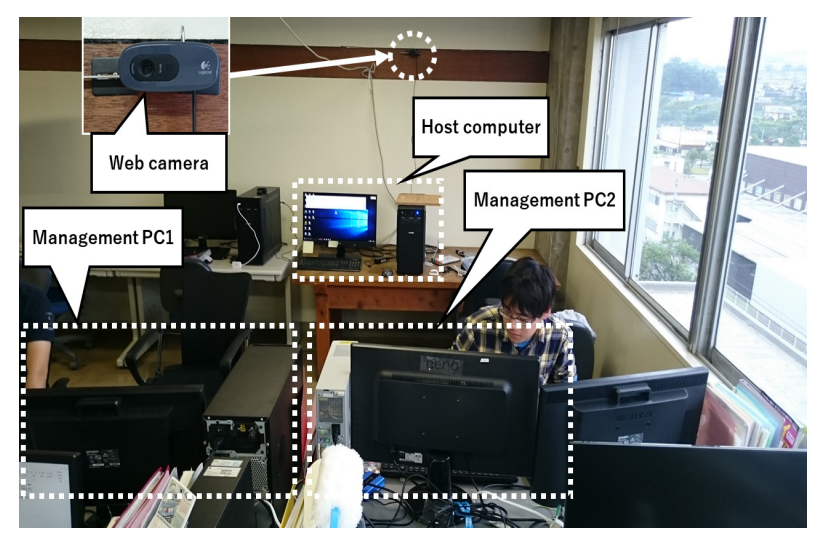

Fig. 7 Experiment image.

no user was at PC 1 (left) while a user was present at PC 2 (right). The moving image from the web camera connected to the host compute was taken in real time as correct answer data.

\subsection{Comparative Evaluation of Camera Data vs. Our Prototype System}

In the proposed method, there are four states ("PC work time", "work time other than PC", "wasted electric use time", and "absence time") for which the period of time can be calculated. The time of each of these four states is calculated by the application on the host computer.

For the initial evaluation, we compared the degree of accuracy of the prototype system with the moving images shot with the camera.

The time values of the four states acquired by the prototype system are shown in Table 2 and Fig. 8.

The result demonstrated that the error was minus one second in both wasted electric use time and absence time, suggesting that those measurements were highly accurate. The total work time (PC work time and working time other than PC) was also found to be fairly accurate, with a minor error of minus 9 seconds. In contrast, there is a large error of about 1 hour in PC work time and work time other than PC. In the prototype system, the "work time other than PC" must be in the state in which the mat sensor is $\mathrm{ON}$ and the PC power is OFF. The large error seems to have occurred because the period of time when the user was performing work other than PC with the power of the
PC turned on was erroneously recorded as "PC work time" by the prototype system.

\subsection{Dependence on PC Sleep Time of Prototype System}

As mentioned in the previous section, the period of time when PC work is performed with the PC power on is recorded as "PC work time". Therefore, we thought that we could more accurately calculate PC work time and work time other than PC by using PC sleep mode. The interval of the sleep time was 1 minute and 10 minutes. Since the PC's sleep mode time setting was at least 1 minute, 1 minute was used in this experiment.

Tables 3 and 4, and Figs. 9 and 10 show that the PC work time calculated by the prototype system and the work time other than PC are closer to the camera time when the sleep time interval is one minute than when 10 minutes. The error is also smaller in 1 minute than in 10 minutes. Namely, both "PC work time" and "work time other than PC" can be accurately obtained if the PC sleep time interval setting is sufficiently short. Setting the sleep time at 1 minute rather than 10 minutes also reduces the wasted electric use time by 10 minutes or even more.

Table 2 Comparative evaluation of camera(video) vs our prototype system.

\begin{tabular}{|c|c|c|c|c|c|}
\hline & $\begin{array}{l}\text { PC work } \\
\text { time }\end{array}$ & $\begin{array}{l}\text { Work time } \\
\text { other than } \\
\text { PC }\end{array}$ & $\begin{array}{l}\text { Total } \\
\text { work time }\end{array}$ & $\begin{array}{l}\text { Wasted } \\
\text { electric } \\
\text { use time }\end{array}$ & $\begin{array}{l}\text { Absence } \\
\text { time }\end{array}$ \\
\hline $\begin{array}{l}\text { Camera } \\
\text { (video) }\end{array}$ & $0: 48: 46$ & 1:06:03 & $1: 54: 49$ & 0:11:26 & $0: 00: 54$ \\
\hline $\begin{array}{l}\text { Prototype } \\
\text { system }\end{array}$ & $1: 54: 41$ & $0: 00: 17$ & $1: 54: 58$ & $0: 11: 25$ & $0: 00: 53$ \\
\hline \multirow[t]{3}{*}{ Error } & $+1: 05: 55$ & $-1: 05: 46$ & $+0: 00: 09$ & $-0: 00: 01$ & $-0: 00: 01$ \\
\hline & \multicolumn{5}{|c|}{ Total work time } \\
\hline & \multicolumn{4}{|c|}{$1: 54: 49$} & 11:26- \\
\hline \multirow[t]{2}{*}{$\begin{array}{l}\text { CAMERA } \\
\text { (VIDEO) }\end{array}$} & \multicolumn{2}{|c|}{ 0:48:46 } & \multicolumn{2}{|c|}{ 1:06:03 } & \\
\hline & & & work time & & 11:25 \\
\hline \multirow[t]{2}{*}{$\begin{array}{l}\text { PROTOTYPE } \\
\text { SYSTEM }\end{array}$} & \multicolumn{4}{|c|}{$1: 54: 41$} & \\
\hline & $\begin{array}{l}\text { PC work tin } \\
\text { Wasted ele }\end{array}$ & e & $\begin{array}{l}\text { Wor } \\
\text { - Abse }\end{array}$ & $\begin{array}{l}\text { stime other } \\
\text { nce time }\end{array}$ & \\
\hline
\end{tabular}

Fig. 8 Comparison between camera image and prototype (not sleep mode). 
Table 3 Sleep time interval 10 minutes.

\begin{tabular}{llllll}
\hline & $\begin{array}{l}\text { PC work } \\
\text { time }\end{array}$ & $\begin{array}{l}\text { Work } \\
\text { time other } \\
\text { than PC }\end{array}$ & $\begin{array}{l}\text { Total } \\
\text { work time }\end{array}$ & $\begin{array}{l}\text { Wasted } \\
\text { electric } \\
\text { use time }\end{array}$ & $\begin{array}{l}\text { Absence } \\
\text { time }\end{array}$ \\
\hline $\begin{array}{l}\text { Camera } \\
\text { (video) }\end{array}$ & $1: 34: 24$ & $0: 25: 19$ & $1: 59: 43$ & $0: 14: 43$ & $0: 01: 37$ \\
$\begin{array}{l}\text { Prototype } \\
\text { system }\end{array}$ & $1: 50: 31$ & $0: 09: 14$ & $1: 59: 44$ & $0: 14: 45$ & $0: 01: 34$ \\
Error & $+0: 16: 07$ & $-0: 16: 05$ & $+0: 00: 01$ & $+0: 00: 02$ & $-0: 00: 3$ \\
\hline
\end{tabular}

Table 4 Sleep time interval 1 minute.

\begin{tabular}{llllll}
\hline & $\begin{array}{l}\text { PC work } \\
\text { time }\end{array}$ & $\begin{array}{l}\text { Work time } \\
\text { other than } \\
\text { PC }\end{array}$ & $\begin{array}{l}\text { Total } \\
\text { work time }\end{array}$ & $\begin{array}{l}\text { Wasted } \\
\text { electric } \\
\text { use time }\end{array}$ & $\begin{array}{l}\text { Absence } \\
\text { time }\end{array}$ \\
\hline $\begin{array}{l}\text { Camera } \\
\text { (video) }\end{array}$ & $2: 22: 45$ & $0: 17: 10$ & $2: 39: 55$ & $0: 02: 24$ & $0: 05: 07$ \\
$\begin{array}{l}\text { Prototype } \\
\text { system }\end{array}$ & $2: 25: 57$ & $0: 14: 47$ & $2: 40: 44$ & $0: 02: 41$ & $0: 04: 55$ \\
Error & $+0: 03: 12$ & $-0: 02: 23$ & $+0: 00: 49$ & $-0: 00: 03$ & $-0: 00: 12$ \\
\hline
\end{tabular}

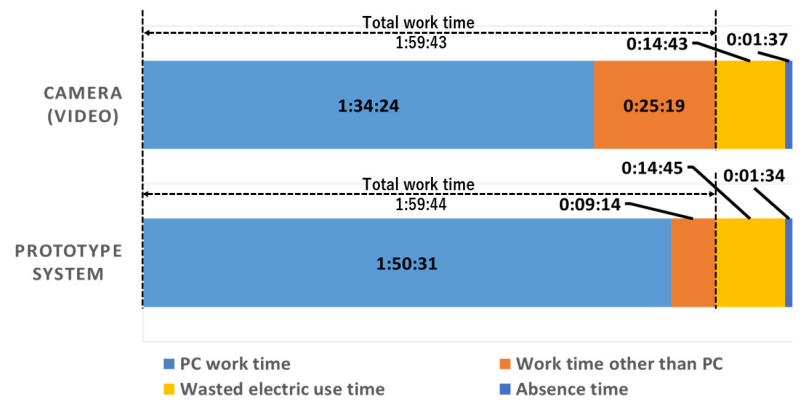

Fig. 9 Result when sleep time is set to 10 minutes.

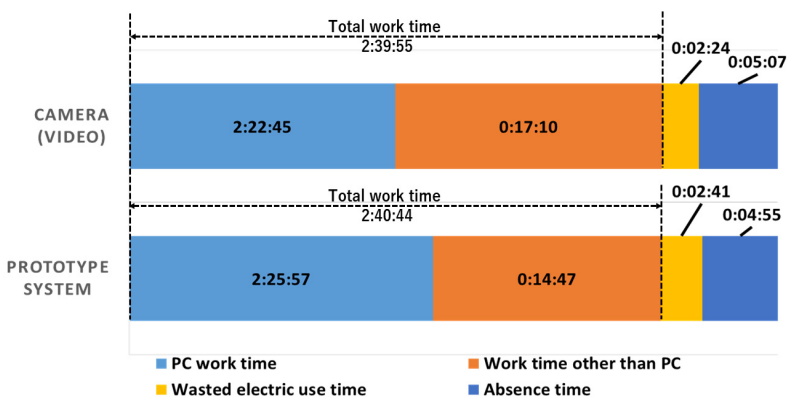

Fig. 10 Result when sleep time is set to 1 minute.

It has been confirmed that the prototype system can more accurately measure PC work time etc. by using the sleep mode of PC. Also, using the sleep mode decreases wasted electric use time, so a power saving effect can be expected.

Setting the PC sleep time to 1 minute of the minimum value makes PC go to sleep soon after PC work is stopped, which is troublesome for PC work.
But in the same time, depending on the computer hardware/software, entering/exiting the sleep mode could take a longer or shorter time, but it is not instantaneous. This client computer takes around $25 \mathrm{~s}$ to put it in sleep and around $5 \mathrm{~s}$ to return to the normal operation mode. So, this sleep transition time is around $30 \mathrm{~s}$ in total. This is also annoying to the PC user.

\subsection{Survey of Stress Questionnaire in PC Sleep Time Setting}

In this proposed system [1], when we used the PC sleep mode, we did a questionnaire about how much inconvenience the user suffered in PC work. This time, PC work stress was evaluated when changing the sleep time of this prototype system to 1 minute and 3 minutes for a total of 19 individuals in their teens and $20 \mathrm{~s}$, including 17 men and 2 women. The reason for setting the sleep time to 3 minutes rather than 10 minutes is to minimize the time to detain the person who answers the questionnaire.

In the prototype system developed this time, we set PC sleeping time to 1 minute and 3 minutes, respectively, and asked them to fill out a questionnaire of 5 grades after doing PC work for about 15 minutes each. We asked the subjects to evaluate the system on
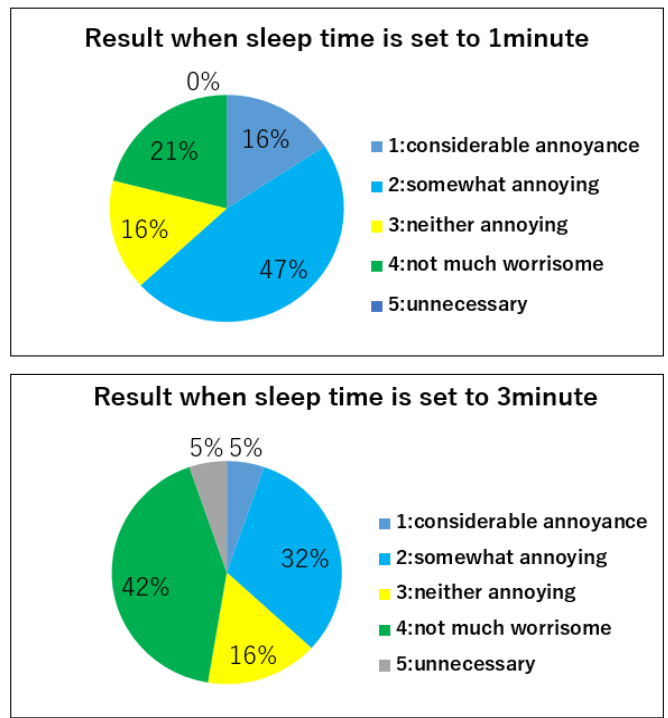

Fig. 11 Result of user's stress survey at PC sleep time setting. 
a 5-point scale: "1: considerable annoyance", "2: somewhat annoying", "3: neither annoying", "4: not much worrisome", "5: unnecessary" . Fig. 11 shows the PC work stress survey results when the sleep time setting is 1 minute and 3 minutes. When the PC sleep time was set to 1 minute, $63 \%$ of people answered " 1 : considerable annoyance" or " 2 : somewhat annoying", whereas the percentage decreased to $37 \%$ when the sleep time setting was 3 minutes.

The above results demonstrate that if the PC sleep time is short in the proposed system, it is annoying for the user to perform PC work.

\section{Conclusions and Future Directions}

In this study, we proposed a method to calculate the four kinds of time ( $\mathrm{PC}$ work time, work time other than PC, absence time, wasted electric use time) from data acquired from a smart tap and mat sensor. We also developed a prototype that implemented this proposed method and conducted a demonstration experiment. As a result, it was possible to accurately obtain the total time of the PC work and the work other than $\mathrm{PC}$, the absence time, and the wasted electric use time. Evaluation experiments revealed that "PC work time" and "work time other than PC" depend on the sleep time of PC. The influence of the PC sleep time on "PC work time" and "work time other than PC" could be decreased by setting a short PC sleep time. The minimum sleep time of the PC is 1 minute, and there is a limit to actually use it. Also, if the sleep time is too short, PC users may feel stressed. In the future, we would like to consider a method that can accurately monitor PC work time without stressing PC users.

Also, our system could be very helpful in doing some analysis of work habits of various categories of users. In the future we would like to study this addition system.

In this evaluation experiment, we conducted with two subjects, but we would like to conduct an evaluation experiment with a large number of people
(PC training room and offices).

\section{References}

[1] Sugihara, T., Fujinami, T., and Nakagawa, K. 2008. "Effects of Cameras and Monitors on Caregivers' Work Stress in the Group Home." The Institute of Electronics, Information and Communication Engineers, IEICE-107, No. 555, WIT 2007-100, 57-62. (in Japanese)

[2] Morita, N. 2012. "Development and Result of Attendance Registration System Using IC Cards." The Institute of Electronics, Information and Communication Engineers (IEICE)/Forum on Information Technology (FIT) 11 (3): 65-8. (in Japanese)

[3] Kubota, S., Furukawa, S., Soejima, Y., Kawamura, R., and Sugitani, K. 2009. "Presence-Type Attendance Management System in Educational PC Classroomss." The Institute of Electronics, Information and Communication Engineers (IEICE)/Forum on Information Technology (FIT) 8 (4): 175-7. (in Japanese)

[4] Suda, H., Nakamura, S., Ogawa, M., Kumazawa, H., and Komdou, N. 2014. "Attendance Management System using Password Distribution of NFC Tag with Electronic Papers." In Proceedings of the 76th National Convention of IPSJ, No.4, pp. 853-4. (in Japanese)

[5] Matsumoto, H., Wada, S., Hara, S., and Morita, N. 2011. "Development and Evaluation of Attendance Registration System using Suicas." Proceedings of the School of Information and Telecommunication Engineering Tokai University 1 (2): 16-21. (in Japanese)

[6] Tanaka, K., and Shuwa, K. 2015. "Application of iBeacon in Laboratory Room Management System Automations." Tokyo City University Yokohama Campus Journal of Information Studies 4 (16): 31-7. (in Japanese)

[7] Takayama, N., and Kitamura, M. 2010. "Hand Free Entry/Attendance Management Systems.” NEC Technical Report 63 (3): 60-3. (in Japanese)

[8] Ono, S., and Yasuda, H. 2014. "Proposal of Setting Management System." In Proceedings of the 2014 IEICE General Conference, p. 184.

[9] Onozawa, K., Watanabe, K., and Suwa, K. 2012. "Room Management System and Learning Situation Management System Using Smartphones." Tokyo City University Yokohama Campus Journal of Information Studies 4 (13): 6-15. (in Japanese)

[10] Nishimura, N. 2013. "New Suddenly Attends.” Journal of Yasuda Women's University 41: 371-9. (in Japanese)

[11] CQ Publishing Companies. 2016. Web brain connection Wi-Fi $\times 3 G / L T E$ of IoTs (In Japanese). Vol. 9, Transistor technology, pp. 35-93. 